\title{
EXPERIMENTAL VERIFICATION OF PUNCHING SHEAR RESISTANCE OF FLAT SLAB FRAGMENTS
}

\author{
Simona Šarvaicová and Viktor Borzovič
}

\begin{abstract}
Slovak University of Technology in Bratislava, Faculty of Civil Engineering, Department of Concrete Structures and Bridges, Bratislava, Radlinského 11, Slovakia; simona.sarvaicova@stuba.sk; viktor.borzovic@stuba.sk
\end{abstract}

\begin{abstract}
The paper deals with the loading test results of an experimental reinforced concrete flat slab fragments, which were supported by an elongated rectangular column. The slab specimens were $200 \mathrm{~mm}$ thick and were designed without any shear reinforcement. During the experimental test, in addition to the shear resistance of the flat slab, deformation state during the whole loading was also examined. Deformations were measured in two ways, using LVDT sensors placed under the slab specimen and by photogrammetric measurement based on measuring the deformations of the code marks glued on the top surface of the specimen. Based on the photogrammetry, it was also possible to determine the concrete strains on the specimen upper surface. The concrete strains on the bottom surface were measured around the column using the strain gauges. By experimentally obtained punching shear resistance, the accuracy of the standard design models for prediction punching resistance was compared. The results of the experiments were also compared with the results of a numerical non-linear analysis performed in the Atena program.
\end{abstract}

\section{KEYWORDS}

Flat slabs, Punching, Shear resistance, Elongated column support, deformation measuring

\section{INTRODUCTION}

Punching shear resistance of locally supported slabs is still a current and discussed topic in the field of assessment of load-bearing structures of buildings. Punching shear of slabs supported on a rectangular column, where we assume an uneven distribution of shear load, has been investigated in many scientific research teams in the Slovak Republic and abroad.

The punching shear resistance of slabs supported by a rectangular column is lower than the shear resistance of slabs supported by a square column with approximately the same length of control perimeter. This phenomenon is due to the fact that the formulas for the evaluation of the punching shear resistance of the slabs include empirical factors that take into account only the geometry of the column, but do not take into account the deformed shape of the slab [1]. In addition to the influence of the column geometry, the influence of various other aspects was investigated, such as the influence of loading conditions or new types of shear reinforcement [2,3].

This research follows an analysis from 2019 [4], when, based on a nonlinear analysis in the Atena program, it was preliminarily concluded that in the case of uniform loading around the entire specimen, the length of the control perimeter is not reduced. In order to confront this statement, the specimen was further analyzed with a $0.15 \mathrm{~m} \times 0.95 \mathrm{~m}$ column, which was subjected to a load test as well as a 3D nonlinear analysis in the Atena program. 


\section{DESIGN MODELS}

\section{Eurocode 2}

The shear resistance in flat slabs without shear reinforcement is ensured by several aspects. It mainly depends on the aggregate interlock in shear crack, compressed concrete area under neutral axis and longitudinal reinforcement. These facts are considered in the empiric formula which determines the punching shear resistance of a slab according to EC2.

where:

$$
V_{\mathrm{Rd}, \mathrm{c}}=\frac{C_{\mathrm{Rk}, \mathrm{c}}}{V_{\mathrm{C}}} k\left(100 \rho_{\mathrm{l}} f_{\mathrm{ck}}\right)^{1 / 3} u_{1} d
$$

$C_{\mathrm{Rk}, \mathrm{c}}$ - empirical factor [MPa];

$\gamma_{C} \quad$ - partial safety factor, $\gamma_{\mathrm{C}}=1.5[-]$;

$k \quad$ - the size factor, $k=1+(200[\mathrm{~mm}] / d)^{0.5} \leq 2.0[-]$;

$\rho_{\mathrm{l}} \quad$ - reinforcement ratio, $\rho=\left(\rho_{\mathrm{x}} \rho_{\mathrm{y}}\right)^{0.5}[-]$;

$f_{\mathrm{ck}} \quad$ - characteristic concrete compressive cylinder strength [MPa];

$u_{1} \quad$ - shear-resisting basic control perimeter at distance of $2 d$ from the face of a column [mm];

$d \quad$ - effective depth [mm].

\section{Model Code 2010}

Model Code 2010 is based on the Critical shear crack theory (Ruiz, Muttoni 2014). The shear resistance which depends on the crack widths is proportional to the slab rotation $\psi$. However, the load rotation is significantly non-linear. This fact was investigated with the result of a quadrilinear moment-curvature diagram which has been simplified for the design application. There are four levels of approximation of rotation calculation around the supported area. For this analysis the Level III of Approximation was used. The values of $r_{\mathrm{s}}$ and $m_{\mathrm{Ed}}$ were calculated from a linear elastic model.

$$
\begin{aligned}
& V_{R d, c}=k_{\psi} \frac{\sqrt{f_{c k}}}{\gamma_{c}} b_{0} d_{v} \\
& k_{\psi}=\frac{1}{1.5+0.9 k_{d g} \psi d} \leq 0.6
\end{aligned}
$$

where:

$k_{\psi} \quad$ - parameter considering rotations of the slab [-];

$b_{0} \quad$ - shear-resisting control perimeter at distance of $0.5 \mathrm{~d}$ from the face of a column [mm];

$d_{v} \quad$ - shear-resisting effective depth [mm];

$k_{\mathrm{dg}} \quad$ - parameter considering the maximum aggregate size, $k_{\mathrm{dg}}=\frac{32}{16+d_{\mathrm{g}}} \geq 0.75[-]$;

$d_{\mathrm{g}} \quad$ - maximum aggregate size $[\mathrm{mm}]$

$\psi \quad$ - slab rotation [-].

$$
\psi=1.2 \frac{r_{s}}{d} \frac{f_{y m}}{E_{s}}\left(\frac{m_{E d}}{m_{R d}}\right)^{1.5}
$$

where:

$r_{\mathrm{s}} \quad$ - the distance from the column's axis to the line of the contraflexure of the radial bending moments [m];

$f_{\mathrm{ym}} \quad$ - yield strength of the main reinforcement [MPa];

$m_{E d} \quad$ - average design bending moment per unit of length $[\mathrm{kNm} / \mathrm{m}]$;

$m_{\mathrm{Rd}} \quad$ - average design bending capacity of a slab per unit of length $[\mathrm{kNm} / \mathrm{m}]$. 


\section{CIVIL}

\section{ENGINEERING}

JOURNAL

\section{prEurocode 2}

This model is also based on the Critical shear crack theory, but the expression of equation is closer to EC2 (2004). More details about this design model are available to see in CEN TC250/SC2.

$$
\begin{aligned}
& V_{\mathrm{Rd}, \mathrm{c}}=\frac{0.6}{\gamma_{\mathrm{C}}} k_{\mathrm{pb}}\left(100 * \rho f_{\mathrm{ck}} \frac{d_{\mathrm{dg}}}{\sqrt{d_{\mathrm{v}} \frac{r_{\mathrm{s}}}{8}}}\right)^{1 / 3} b_{0} d_{\mathrm{v}} \\
& k_{\mathrm{pb}}=\sqrt{5 \cdot \mu_{\mathrm{p}} \frac{d_{\mathrm{v}}}{b_{0}}}<2.5
\end{aligned}
$$

where:

$d_{d g} \quad$ - a size parameter which describes the failure zone roughness considering the concrete class and aggregate properties; $d_{\mathrm{dg}}=16 \mathrm{~mm}+d_{\mathrm{g}, \max } \leq 40 \mathrm{~mm}$ if $f_{\mathrm{ck}} \leq 60 \mathrm{MPa}[\mathrm{mm}]$;

$\mu_{\mathrm{p}} \quad$ - a coefficient accounting for the shear force gradient and bending moments in the region of the control perimeter, for internal column: $\mu_{\mathrm{p}}=8 / k_{\mathrm{e}}[-]$;

$k_{\mathrm{e}} \quad-$ a factor considering an influence of reduced control perimeter, $k_{\mathrm{e}}=b_{0} / b_{0, \text { red }}[-]$;

$b_{0, \text { red }} \quad$ - reduced control perimeter due to significantly elongated cross-section of a column [mm].

\section{The non-linear analysis}

The non-linear analysis was performed in Atena - program based on finite element method [5]. Several research teams dealt with non-linear analysis in Atena, including [6], who focused on the strengthening of flat slabs. According to the linear analysis, there is a partial decrease in shear forces at a distance of $1.5 d$ from the support corners [4]. Figure 1 shows the decrease in shear forces of a specimen supported by a column with cross-sectional dimensions of $950 \times 150 \mathrm{~mm}$ using different loading conditions. However, in the non-linear analysis, the reduction of the control perimeter length was not demonstrated despite the fact that the ratio of the longer column cross-sectional dimension to the effective depth was $c_{\max } / d>3$. This phenomenon is caused by several aspects including redistribution of stresses around the support. Model calibration was implemented on the basis of previous experiments [7].

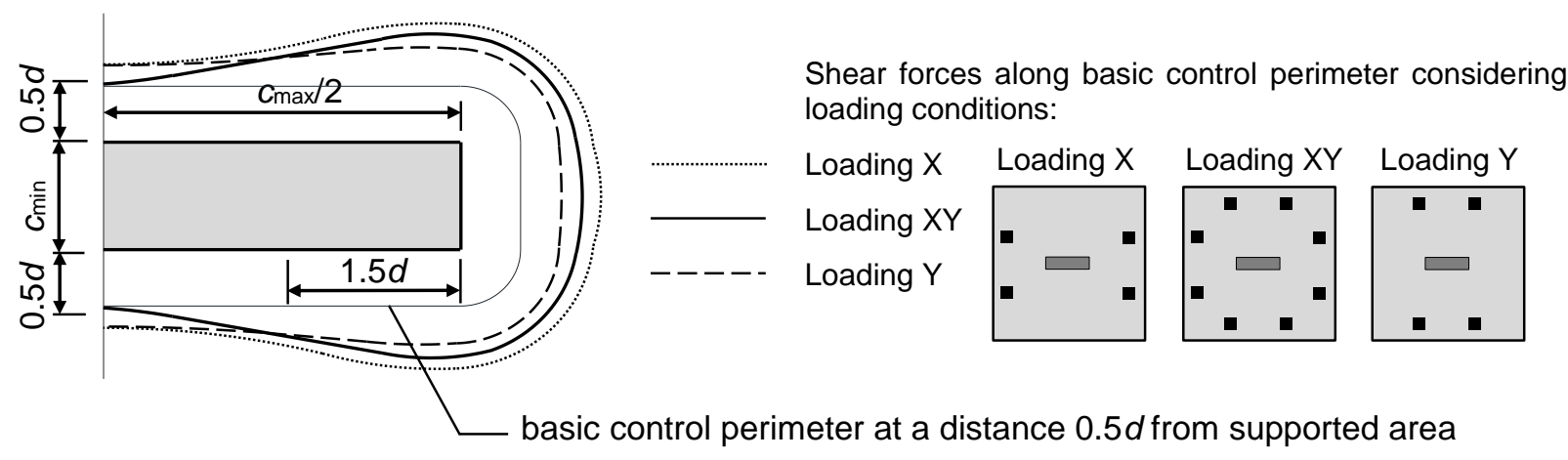

Fig. 1 - The distribution of shear forces along the basic control perimeter

Because 3D non-linear evaluations are time consuming, symmetry conditions were used and only a quarter of the whole specimen was modeled (Figure 2). 


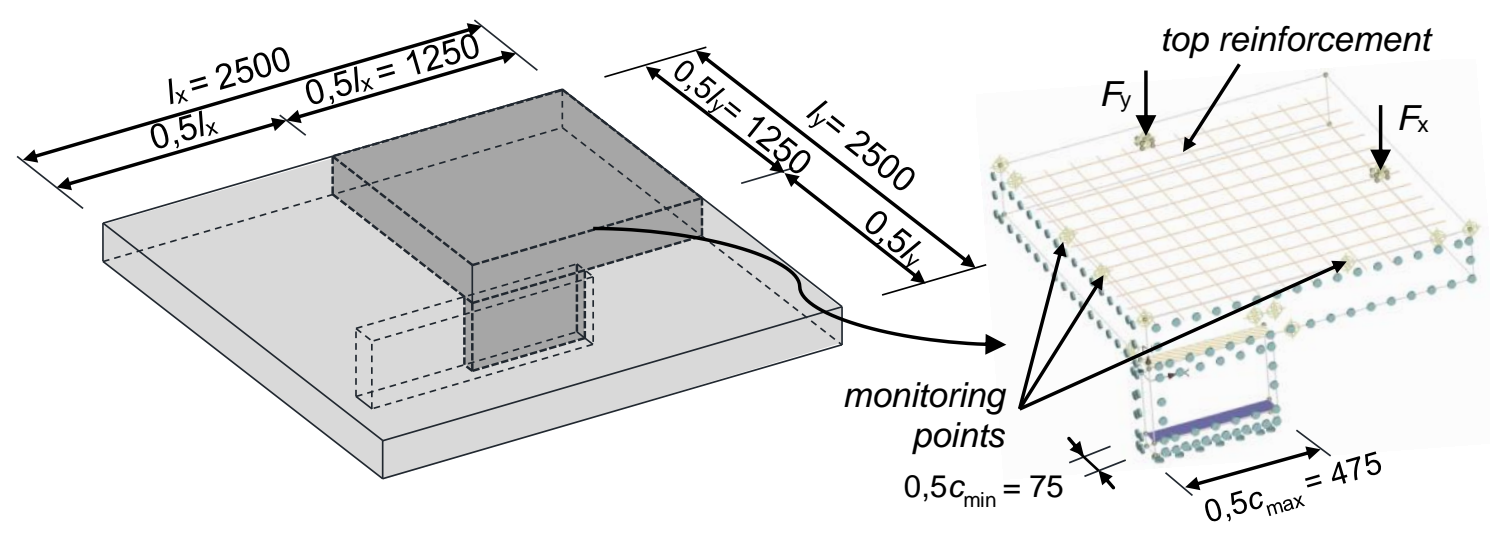

Fig. 2 Fragment model of specimen modeled in Atena

\section{EXPERIMENTAL PROGRAM}

\section{Experimental specimens}

The size of test specimens was $2.5 \mathrm{~m} \times 2.5 \mathrm{~m}$ with thickness of $0.2 \mathrm{~m}$. These dimensions are based on laboratory conditions and the overall arrangement of the experimental set-up. Concrete samples were taken during the concreting to determine the material properties. The measured concrete cylinder strength at time of testing is listed in Table1. The maximum aggregate size $d_{g}$, max $=16 \mathrm{~mm}$ was used. The slab fragment was reinforced with steel reinforcement of B500B with yield strength $f_{y m}=550 \mathrm{MPa}: 16 \mathrm{~mm}$ diameter bars equally spaced at $100 \mathrm{~mm}$ in both orthogonal directions and $10 \mathrm{~mm}$ bars equally spaced at $200 \mathrm{~mm}$ on the compression face. The specimens were not reinforced with transverse reinforcement. Other specimens' characteristics are listed in Table1.

The concrete of supporting column reached $89 \mathrm{MPa}$ of cylinder strength. It is reinforced with 12 bars with diameter $\varnothing=12 \mathrm{~mm}$ spaced evenly along the column perimeter.

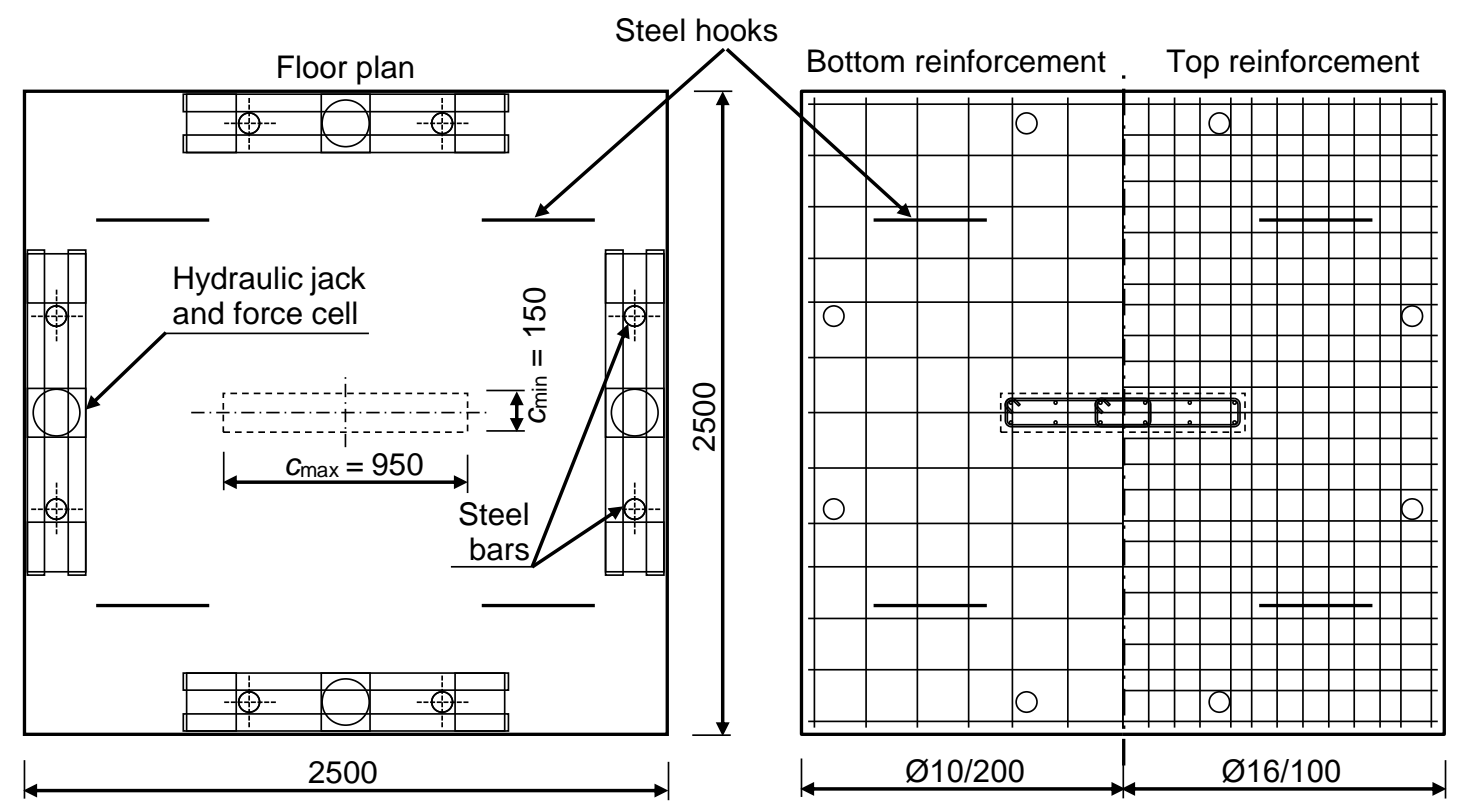

Fig. 3 - Geometry and reinforcement of experimental specimen 
Tab. 1 - Specimen's characteristics

\begin{tabular}{|c|c|c|c|c|c|c|c|}
\hline \multirow{2}{*}{ Test } & \multirow{2}{*}{$f_{\mathrm{c}}[\mathrm{MPa}]$} & \multicolumn{2}{|c|}{$c_{\text {nom }}[\mathrm{m}]$} & \multirow{2}{*}{$d[\mathrm{~m}]$} & \multirow{2}{*}{$\rho[\%]$} & \multicolumn{2}{c|}{ Reinforcement } \\
\cline { 3 - 4 } \cline { 6 - 8 } & & Top & Bottom & & & Top & Bottom \\
\hline D00 & 29.9 & 0.025 & 0.02 & 0.159 & 1.26 & $\varnothing 16 / 100$ & $\varnothing 10 / 200$ \\
\hline D01 & 22.3 & 0.02 & 0.02 & 0.164 & 1.26 & $\varnothing 16 / 100$ & $\varnothing 10 / 200$ \\
\hline
\end{tabular}

\section{Experimental set-up}

The experimental set-up consists of four hydraulic jacks placed around the specimen perimeter, which are spread by a system of beams. These beams are made of two UPE profiles which are fixed to steel bars ( $\varnothing=42 \mathrm{~mm}$ ) placed among them and anchored to the laboratory floor. Concentrated forces are transferred from the hydraulic jacks to the bottom distribution pair of beams, which are supported with calottes to ensure joint connection of the frame and specimen.

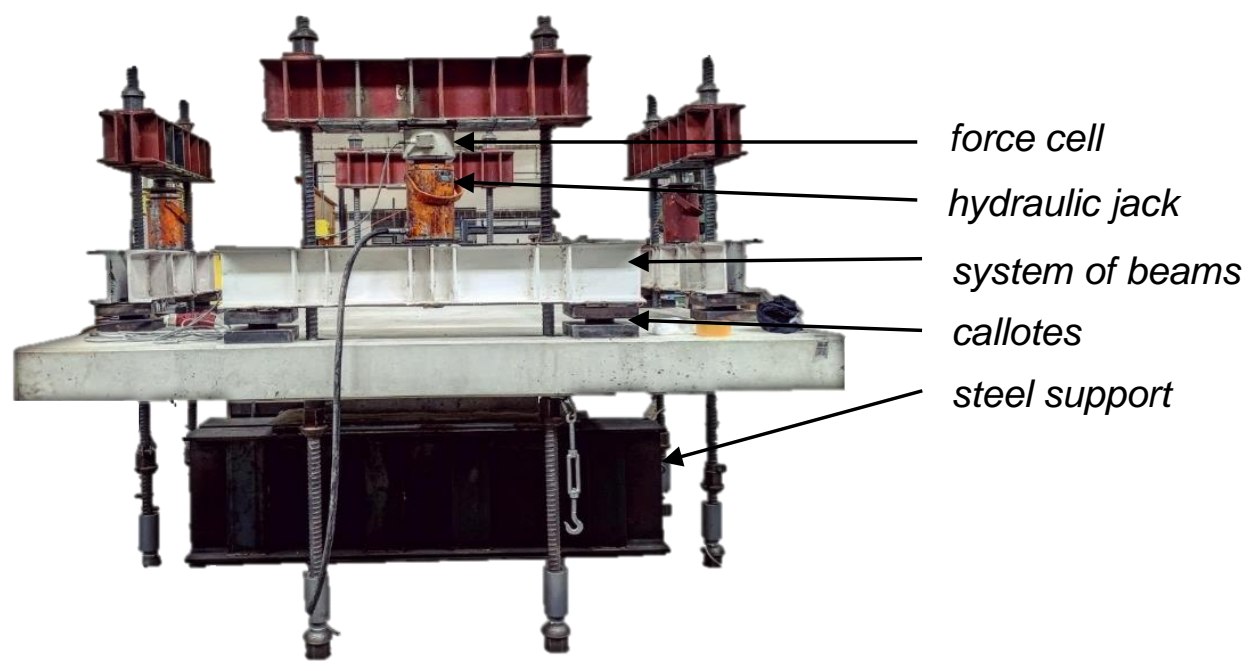

Fig. 4 - Experimental set-up

\section{Loading conditions}

The first loading step of approximately $20 \mathrm{kN}$ was performed to activate the experimental setup. Gradually even loading of the specimen was performed in individual loading steps of $50 \mathrm{kN}$ and $100 \mathrm{kN}$, i.e. $12.5 \mathrm{kN}$ (or $25 \mathrm{kN}$ ) per one hydraulic jack. Just before the expected failure, the loading step was reduced to $25 \mathrm{kN}$. Short pauses were taken between the individual steps to stabilize the specimen deformations, to record photos for the photogrammetry measurement and to draw newly occurred cracks.

\section{Measuring devices}

The concentrated load in the form of eight forces distributed around the specimen perimeter was measured by four load cells connected to one hydraulic system. The loading force from one hydraulic jack was applied to the specimen at two points with a mutual distance of approximately 1 $\mathrm{m}$ (distance of steel calottes).

Several measuring devices were also installed on the specimen, recording its deformation behavior during the entire process of loading until its failure. Strain gauges were glued to the bottom 


\section{CIVIL}

ENGINEERING JOURNAL

surface around the support according to the scheme in Figure 5a. Using the strain gauges, it was possible to determine the concrete strains both in the radial and tangential direction. Specimen deformations were measured in two directions using LVDT sensors located in the slab axis lines (Figure $4 \mathrm{~b}$ ). The full stroke range of used LVDT sensors varies from $50 \mathrm{~mm}$ located close to column to $300 \mathrm{~mm}$ located between to steel rods. The deflection measured in millimeters could be determined up to an accuracy of five decimal places.
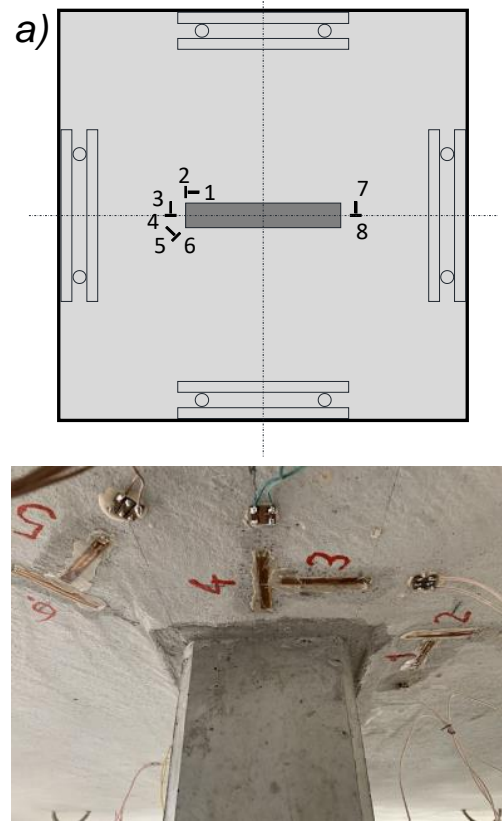

b)

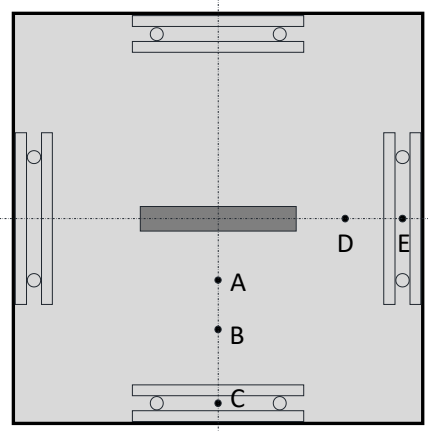

c)
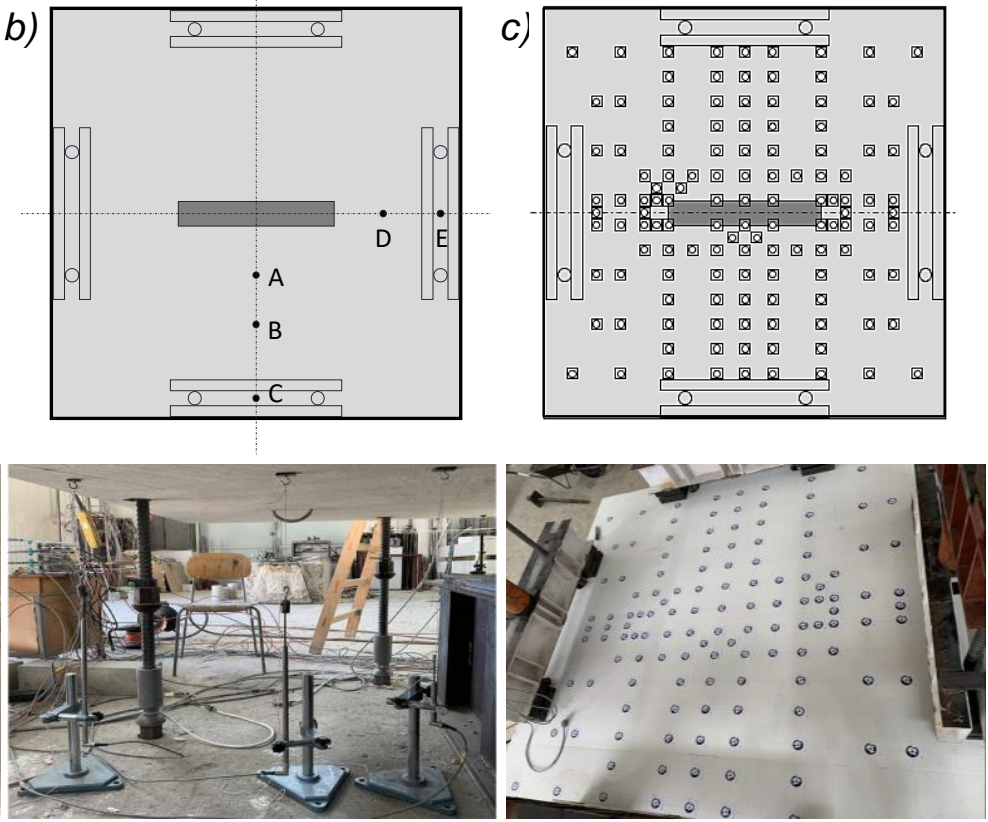

Fig. 5 - The sensor layout scheme: a) strain gauges b) LVDT sensors c) code marks on the top surface of the specimen used for convergent photogrammetry measurement

In cooperation with the Department of Geodesy in Faculty of civil engineering of Slovak university of technology in Bratislava, a method of measurement using convergent photogrammetry was implemented in this experimental test. Multi-image convergent photogrammetry was performed to achieve 3D coordinates of observed points [8]. The Nikon D800E DSLR camera (full frame 36 Mpixel sensor) equipped with a Nikkor 35mm AF-S ED 1:1.8G lens was used to take photos around the specimen in each loading step (Figure 6). To eliminate the blur motion caused by poor illumination conditions, an external flash was used. An exposure time of 1/250 s was achieved at the following camera settings: aperture priority - F/8, ISO 200, autofocus. 

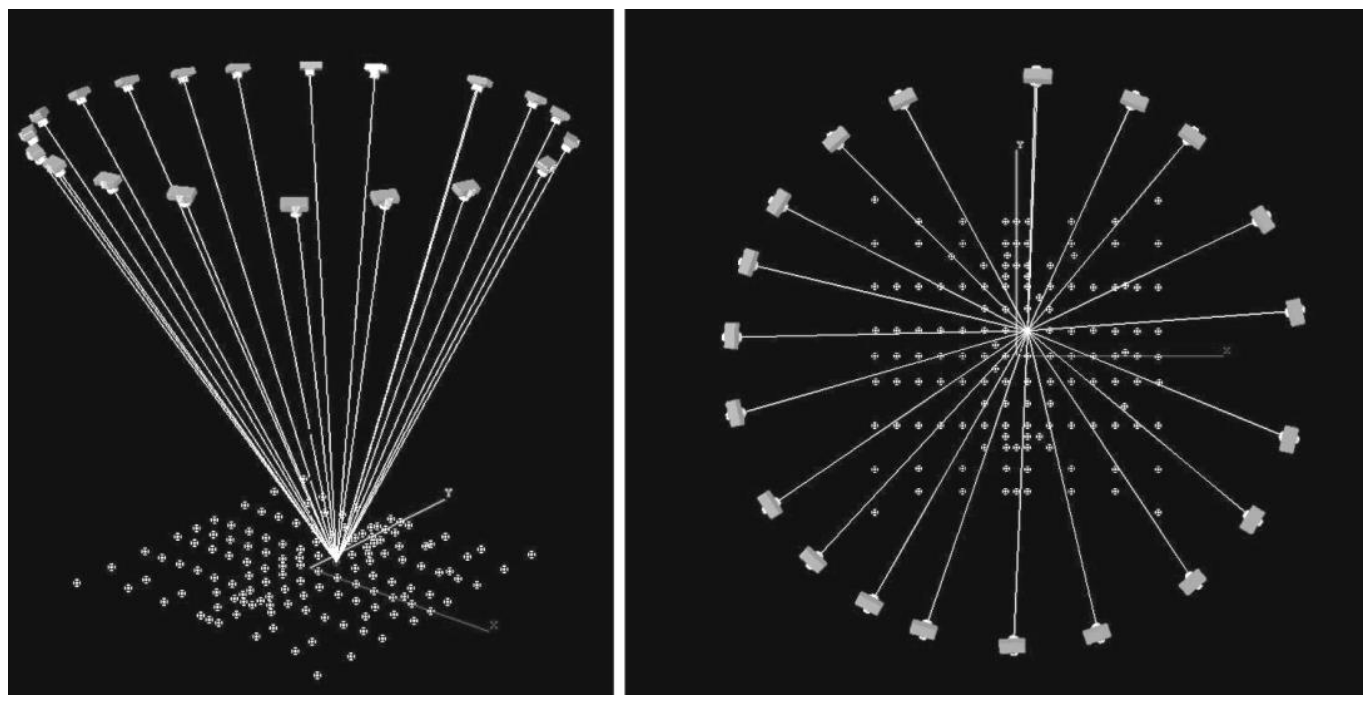

Fig. 6 - Image configuration - axo view (left) and top view (right)

131 observed points were signalized by RAD (Ringed Automatically Detected) coded targets, which enable automatic detection and measurement with subpixel precision. Images were processed by Photomodeler Software [9] on the principles of bundle block adjustment. The project scale was determined using two scale bars attached to the specimen surface - the length of the scale bars was derived from the calibration plate of the Comet L3D scanner with an accuracy of 0.01 $\mathrm{mm}$. The results of photogrammetric processing are shown below.

Tab. 1 - Multi-image convergent photogrammetry precision details

\begin{tabular}{|c|c|c|c|c|c|}
\hline Precision [mm] & $\begin{array}{c}\text { Number of } \\
\text { photos per } \\
\text { loading step }\end{array}$ & $\begin{array}{c}\text { Angle } \\
\text { intersection } \\
\text { [deg] }\end{array}$ & $\begin{array}{c}\text { Rays per } \\
\text { points }\end{array}$ & $\begin{array}{c}\text { Max. } \\
\text { residual } \\
\text { [pix] }\end{array}$ & $\begin{array}{c}\text { RMS residual } \\
\text { [pix] }\end{array}$ \\
\cline { 1 - 3 } $\mathrm{m}_{\mathrm{x}}=0.003-0.008$ & 20 & $51-57$ & $7-21$ & 0.21 & 0.04 \\
\hline $\mathrm{m}_{\mathrm{y}}=0.003-0.010$ & 20 & & & \\
\hline $\mathrm{m}_{\mathrm{z}}=0.007-0.014$ & & & & & \\
\hline
\end{tabular}

\section{TEST RESULTS}

The failure was fragile in both experimental tests, indicating that the collapse of the specimen was due to the achievement of shear resistance. The experimentally obtained values of shear resistance were compared to selected design models, which verified their reliability (Table 2). The $V_{\text {test }}$ given in Table 2 is the sum of the maximum forces measured in the load cells and the body force of the specimen with a value of $31 \mathrm{kN}$. 
CIVIL

ENGINEERING

JOURNAL

THE CIVIL ENGINEERING JOURNAL 4-2021

Tab. 2: Results obtained from experimental test and Atena compared to design models

\begin{tabular}{|c|c|c|c|c|c|c|c|c|c|c|}
\hline & \multirow{2}{*}{\multicolumn{2}{|c|}{$\begin{array}{l}\text { Basic control } \\
\text { perimeter }[\mathrm{m}]\end{array}$}} & \multicolumn{4}{|c|}{$\begin{array}{c}\text { Punching shear resistance } \\
{[\mathrm{kN}]}\end{array}$} & \multirow{2}{*}{\multicolumn{2}{|c|}{ D00 }} & \multirow{2}{*}{\multicolumn{2}{|c|}{ D01 }} \\
\hline & & & \multicolumn{2}{|c|}{ D00 } & \multicolumn{2}{|c|}{$\mathrm{D} 01$} & & & & \\
\hline & $u_{1}$ & Ured $^{*}$ & $V_{\mathrm{R}, \mathrm{C}}$ & $V_{\mathrm{R}, \mathrm{c}, \text { red }}$ & $V_{\mathrm{R}, \mathrm{C}}$ & $V_{\mathrm{R}, \mathrm{c}, \mathrm{red}}$ & $\begin{array}{l}V_{\text {test }} / \\
V_{\mathrm{R}, \mathrm{c}} \\
\end{array}$ & $\begin{array}{l}V_{\text {test }} / \\
V_{\text {R,c,red }} \\
\end{array}$ & $\begin{array}{c}V_{\text {test }} / \\
V_{\mathrm{R}, \mathrm{c}} \\
\end{array}$ & $\begin{array}{l}V_{\text {test }} / \\
V_{\text {R,c,red }} \\
\end{array}$ \\
\hline Test & \multicolumn{2}{|c|}{4.07} & \multicolumn{2}{|c|}{852} & \multicolumn{2}{|c|}{688} & \multicolumn{2}{|c|}{-} & \multicolumn{2}{|c|}{-} \\
\hline Atena & \multicolumn{2}{|c|}{4.09} & \multicolumn{2}{|c|}{875} & \multicolumn{2}{|c|}{721} & \multicolumn{2}{|c|}{0.97} & \multicolumn{2}{|c|}{0.95} \\
\hline EC2 [10] & 4.20 & 3.25 & 856 & 663 & 794 & 623 & 0.99 & 1.29 & 0.87 & 1.10 \\
\hline prEC2 [11] & 2.70 & 1.75 & 778 & 628 & 723 & 588 & 1.09 & 1.36 & 0.95 & 1.17 \\
\hline MC2010 [12] & 2.70 & 1.75 & 760 & 590 & 707 & 552 & 1.12 & 1.44 & 0.97 & 1.25 \\
\hline
\end{tabular}

Based on the shear strength obtained from the experiment and non-linear analysis, the length of the control perimeter was derived using the shear resistance evaluation formula according to EC2 [10].

The concentration of shear forces around the corners of the support can be confirmed by the formation of the first appeared shear cracks in this area. First, radial cracks formed and with increasing load were joined by newly formed tangential cracks. However, by comparing the experimentally obtained shear resistance with the values according to the design models, the necessity to reduce the length of the control perimeter was demonstrated for both specimens compared to selected design models, as their reliability reaches 0.87 to 1.12 considering the full length of control perimeter.

\section{Deformations}

Figure 7 shows specimen deformations in the lines of the main axes. According to design model EC2, a slab supported by a square column would have the same shear resistance as a slab supported by a column with a rectangular cross-section with the same length of control perimeter. The EC2 design model therefore only takes into account the length of the control perimeter, not the geometry of the support. However, by comparing the deformation courses of the slab, the influence of the column geometry on its shear resistance can be confirmed. Significantly larger deflection of the specimen was measured in the direction perpendicular to the longer side of the column $c_{\max }$.
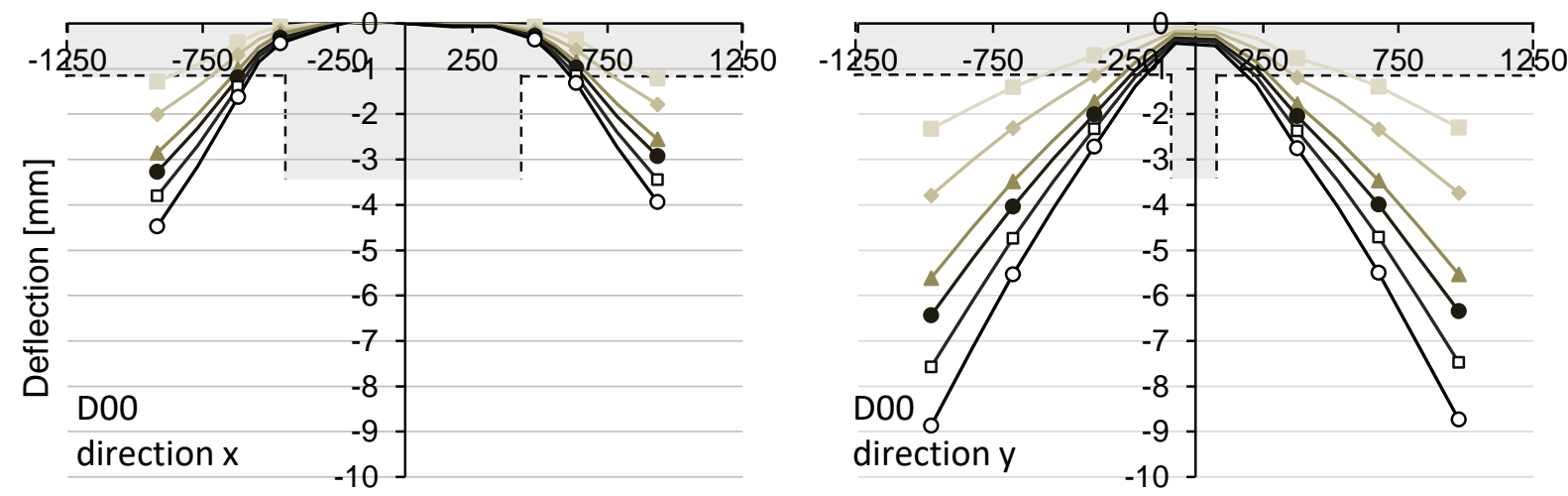

Fig. 7 - Deflected profiles of the specimens 
CIVIL
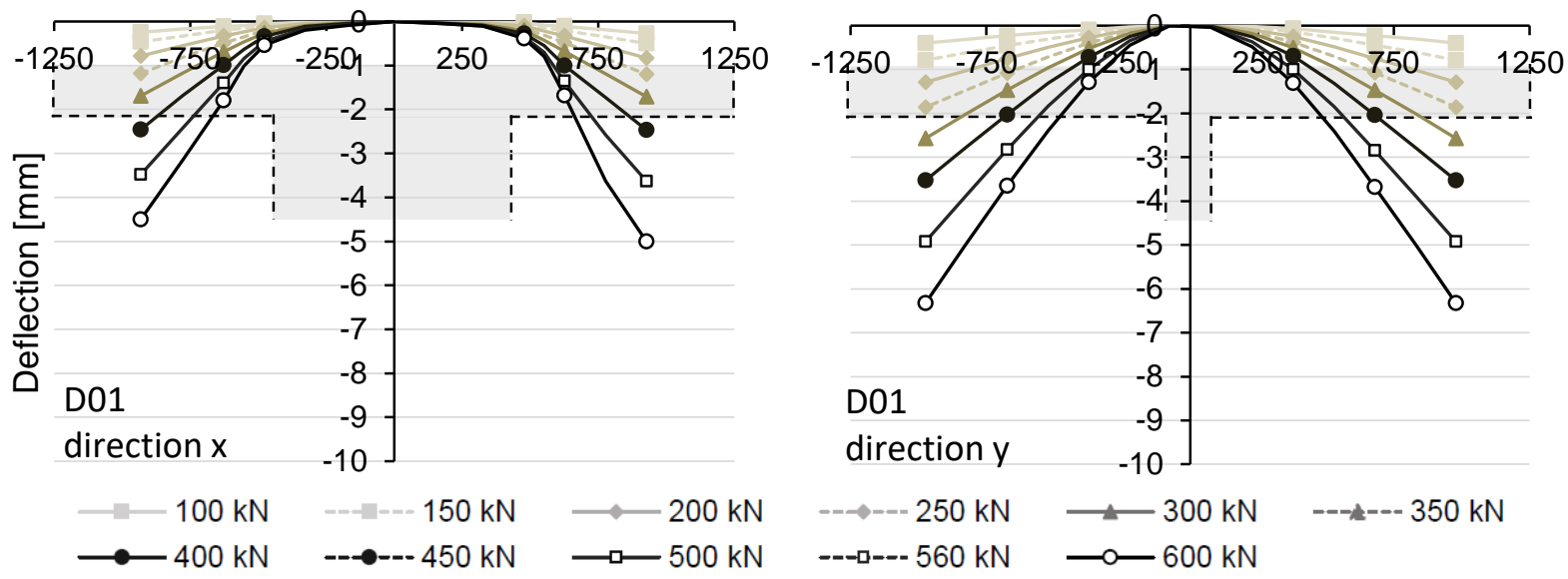

Fig. 8 - Deflected profiles of the specimens
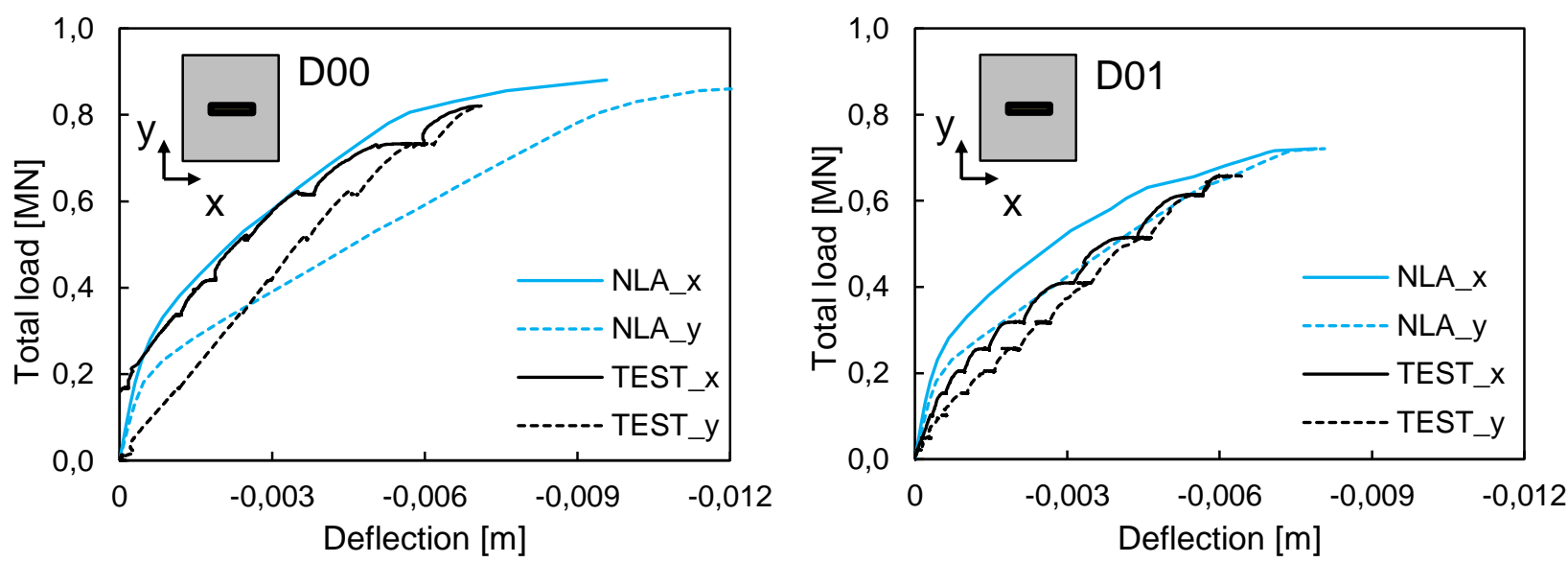

Fig. 9 - Maximum deflection evaluated in NLA compared to maximum deflection measured in experimental test ( $L V D T$ at $C$ and $E$ points according to Figure $5 b$ )

In the case of specimen D00, the deflection in the direction perpendicular to the longer side of the column reached significantly higher values. This phenomenon is caused by the fact that the drawn deflection is already captured on the specimen with developed cracks, which arose as a result of previous loading, which had to be suspended and the specimen was unloaded again.

\section{Strains}

The concrete strains on the top surface of the specimen were evaluated on the basis of the results of photogrammetric measurements. The maximum strains reached a value of up to $4.1 \%$. Figure 8 shows the course of the concrete strains in the individual loading steps. On the top surface of the slab, no significant differences were observed in the concrete strains in the section through the center of the longer side of the column compared to the area of its corners. 

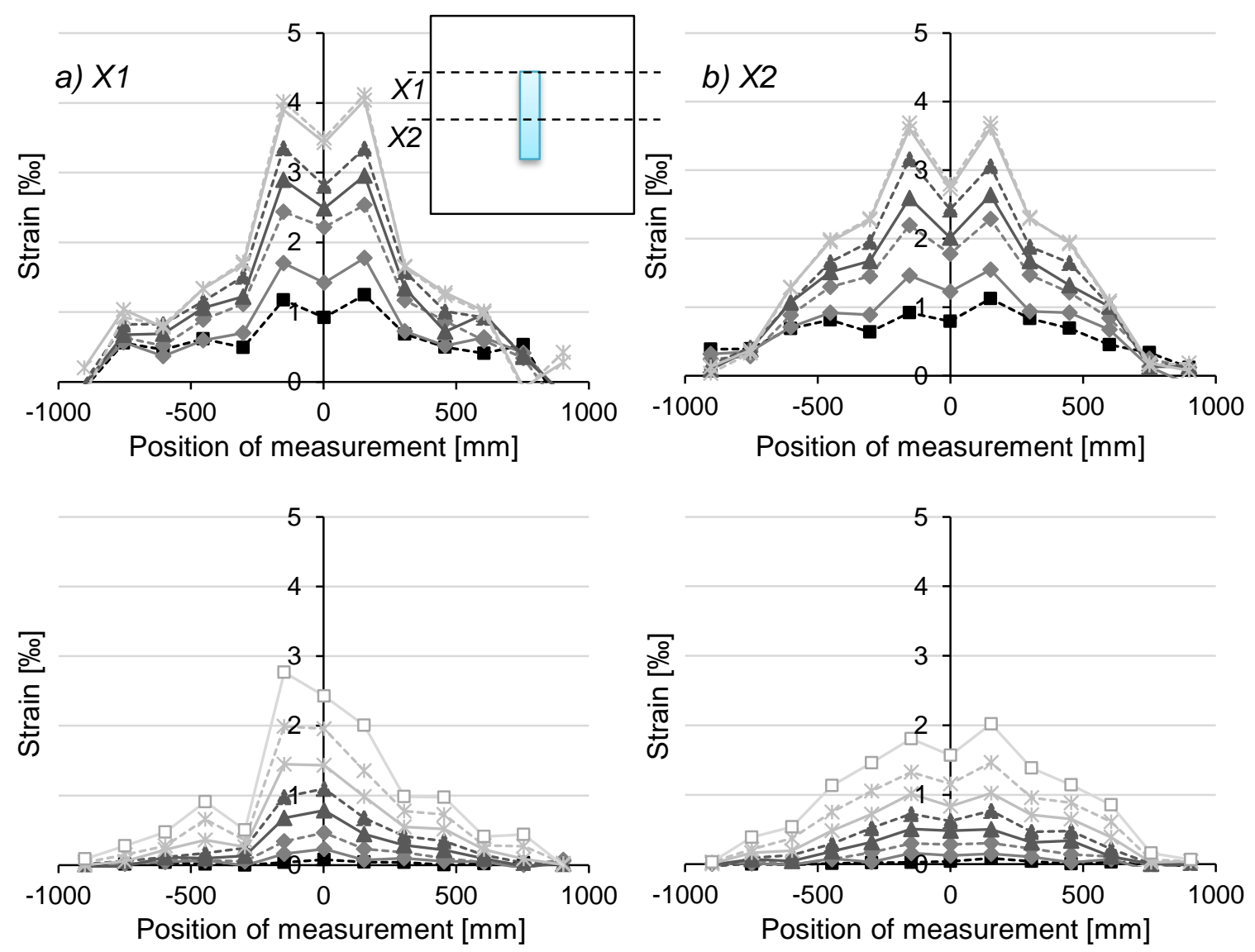

Fig. 10 - Concrete strains (\%o) on the top surface of the specimen in the direction of the $x$-axis in individual loading steps

The concrete strains were measured on the bottom surface of the specimen in the area around the support using strain gauges glued in both the radial and tangential directions according to the diagram in Figure 5a. The largest concrete strains were measured in the tangential around the corners of the support (strain gauges no. 3 and 7 ), on the contrary, the contrary, the concrete strains in the radial direction reached the lowest values at these points (Figure 10). 

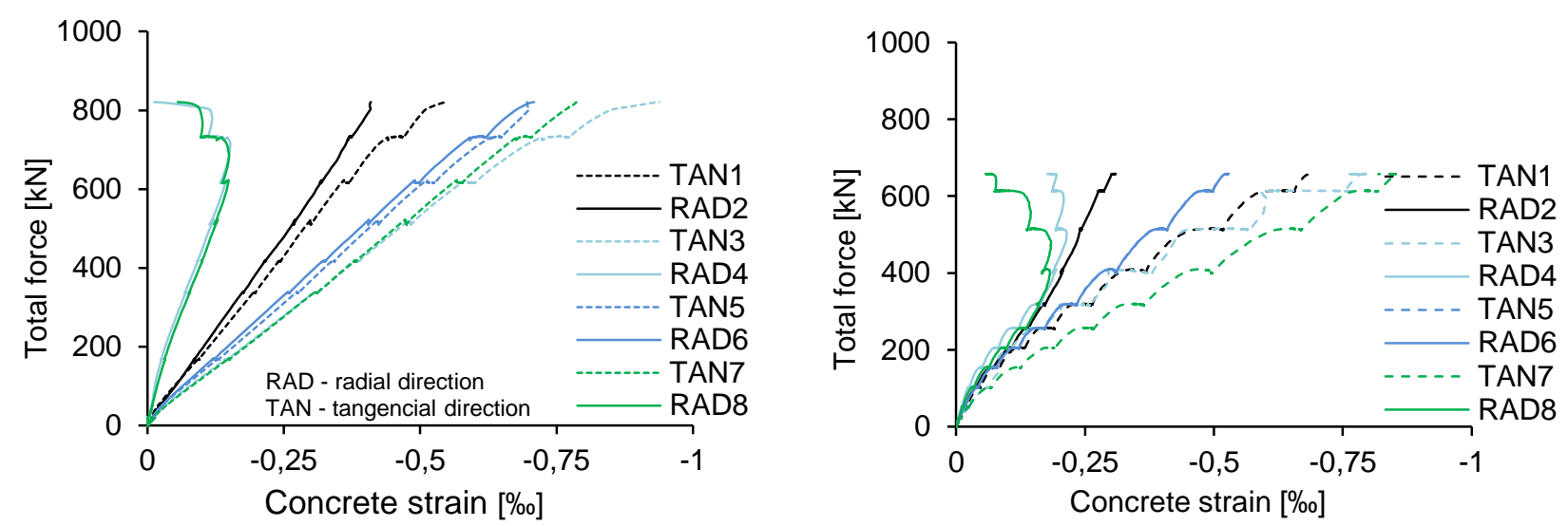

Fig. 11 - Concrete strains on the bottom surface of the specimen measured in strain gauges

\section{CONCLUSION}

The subject of this paper is to acquaint with the results of experimental tests of slab fragments supported by a rectangular column, the results of which were confronted with numerical nonlinear analysis and predictions according to selected design models. Based on these comparisons, the following conclusions were derived:

1. Both experimental tests and non-linear analysis shown the necessity to reduce the length of the control perimeter. Compared to the design models EC2, MC2010 and prEC2 (2018), reliability reaches from 0.87 to 1.12 considering the full length of the control perimeter for this support geometry and uniform loading.

2. The formation of the first cracks in the radial direction was recorded around the corners of the support, thus demonstrating the stress concentration in these areas.

3. The largest concrete strains on the bottom surface of the specimen were measured in the tangential direction at points near the corners of the support.

4. Measured deformations in the $x$ and $y$ directions were compensated just before the failure, which seems to be a results of forces redistribution. A similar result was demonstrated by Atena in the case of specimen D01.

5. Photogrammetric measurement records the whole deformation behavior of the specimen in contrast to LVDT sensors located at specific points. The results obtained from non-linear analysis have shown better agreement to actual slab behavior observed in experimental test than the photogrammetric measurement in the case of specimen D01.

\section{ACKNOWLEDGEMENTS}

This work was supported by the Slovak Research and Development Agency under the contract No. APVV-15-0658 and Scientific Grant Agency of the Ministry of Education, science, research and sport of the Slovak Republic and the Slovak Academy of Sciences No 1/0645/20.

\section{REFERENCES}

[1] Sagaseta J., Tassinari L., Fernández Ruiz M., Muttoni A., 2014. Punching of flat slabs supported on rectangular columns. Engineering Structures 77: 17-33. 
[2] Mečár J., Bujňáková P., Sobek V., 2019. Optimized design of flat slabs with different novel type of punching reinforcement, In: Proc. International Conference on Sustainable Materials, Systems and Structures, Challenges in Design and Management of Structures, 18-23.

[3] Sucharda O., Smirakova M., Vaskova J., Mateckova P., Kubosek J., Cajka R., 2018. Punching Shear Failure of Concrete Ground Supported Slab. In: International Journal of Concrete Structures and Materials, 12(1).

[4] Šarvaicová S., Borzovič V., Augustín T., 2019. The influence of a column shape cross-section on the punching capacity. In: MBMST 2019 conference proceeding. 455-462.

[5] Červenka V., Jendele L., Červenka J., 2018. ATENA program documentation, Part 1, Theory. (Prague: s.n).

[6] Nováček J., Zich M., 2016. Study of Flat Slabs Strengthening against Punching Shear. In: Solid State Phenomena 249. 221-226.

[7] Augustín T., Fillo L'., Halvonik J., 2019. Punching resistance of slab-column connections with openings, Structural Concrete 21, 278-290.

[8] Marčiš M., Fraštia M., Bajtala M., Augustín T., 2017. Measurement of flat slab deformations by the multi-image photogrammetry method. In: Slovak Journal of Civil Engineering. Vol. 25, no. 4, 19-25.

[9] https://www.photomodeler.com/

[10] European Commitee for Standardization. Eurocode 2: Design of concrete structures, Part 1-1: General rules and rules for buildings, 2004.

[11] prEN 1992-1-1 Eurocode 2: Design of concrete structures - Part 1-1: General rules, rules for buildings, bridges and civil engineering structures. Review 11. Upgrated draft D5. 2020.

[12] Fédération Internationale du Béton (fib). Bulletin n. 65/66 Model Code 2010. Final draft (Vol. 1, 2. fib). Lausanne, 2012. 